\title{
DR-31. PREPARATION OF MONOETHANOLAMINE AND 5-PHENYL-2,2'-BIPYRIDINE DERIVATIVES AND THEIR SUBSEQUENT TOSYLATION REACTIONS
}

\author{
$\underline{\text { D. S. Kopchuk }}^{1,2}$, I. S. Kovalev ${ }^{1}$, S. Santra ${ }^{1}$, G. V. Zyryanov ${ }^{1,2}$, V. L. Rusinov ${ }^{1,2}$, \\ O. N. Chupakhin ${ }^{1,2}$, V. N. Charushin ${ }^{1,2}$ \\ ${ }^{1}$ Ural Federal University of the first President of Russia B. N. Yeltsin, \\ Mira St., 19, Yekaterinburg, 620002, Russia \\ ${ }^{2}$ I. Ya. Postovsky Institute of Organic Synthesis UB RAS,
} S. Kovalevskoy / Akademicheskaya St., 20/22, Yekaterinburg, 620990, Russia.

E-mail: dkopchuk@mail.ru

Oxazolidine derivatives are of interest as biologically active compounds, as well as catalysts for enantioselective reactions. Separately, in this aspect, it should be noted that a fragment of $\mathrm{N}$-tosyloxazolidine is presented in a number of biologically active structures. To form the oxazolidine cycle, we used a reaction of monoethanolamine-based Schiff base with tosyl chloride. To date, there are very few examples of such syntheses. In this publication, we propose an approach to $\mathrm{N}$-tosyloxazolidine derivatives having a 2,2'-bipyridine fragment.

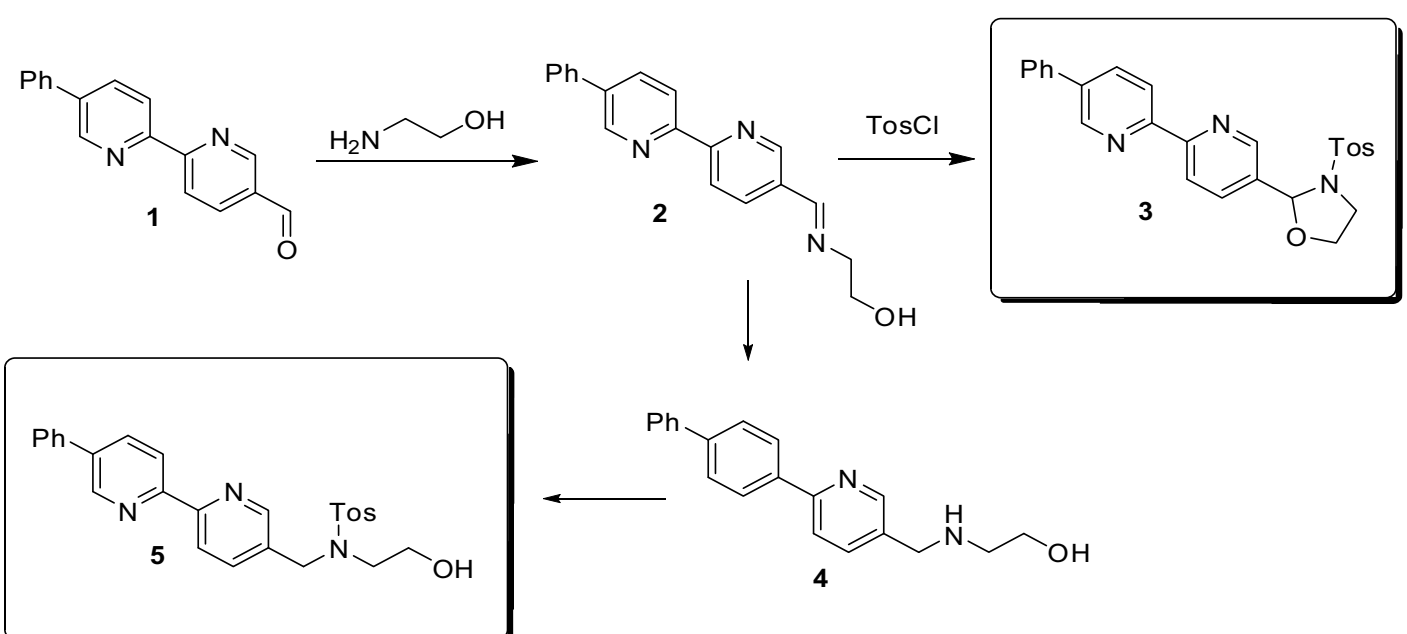

This work was supported by the Russian Science Foundation (Ref. № 18-73-00301). 